\title{
O que nos dizem as imagens que vêm os nossos alunos: Uma reflexão sobre as imagens que os professores de arte mostram aos seus alunos
}

What are telling us the images our students are seeing: A reflection on the images that Art teachers present to their students

Ricardo Reis

Universitat de Barcelona

\section{Resumo}

O presente texto apresenta preliminarmente um conjunto de procedimentos de investigação a integrar uma tese de doutoramento que foi iniciada na Universidade de Barcelona, em Espanha. A pesquisa tem por objectivo indagar sobre o papel da escola no desenvolvimento e valorização social da literacia visual. O trabalho mapeia um conjunto de autores que, nos últimos anos, têm se dedicado sobre o tema e procura caracterizar algumas práticas de visualidade que hoje se realizam nas escolas portuguesas.

Palavras-chave: literacia visual; imagens; docência em arte, direcionalidade

\section{Abstract}

This paper preliminarily presents a set of investigative procedures to integrate a PhD thesis that was initiated at the University of Barcelona in Spain. The research presents as main objective to inquire about the school's role in social development and enhancement of visual literacy. The work maps a set of authors who, in recent years, have been dedicating themselves to the topic and seeks to characterize some visual practices which are held today in Portuguese schools.

Keywords: visual literacy; images; art teaching, directionality

Porque é importante saber que imagens foram mostradas aos alunos?

As imagens são estímulos poderosos para a mente humana. Isso mesmo foi reconhecido e utilizado como instrumento de persuasão e dispositivo de poder muito antes da invenção dos meios de comunicação de massas. As imagens estão por toda a parte mas não aparecem simplesmente, são produzidas em diferentes contextos

Revista Digital do LAV - Santa Maria - vol. 9, n. 1, p. 5 - 15. - jan./abr. 2016 ISSN 1983 - 7348 http://dx.doi.org/10.5902/1983734821765 
O que nos dizem as imagens que vêm os nossos alunos: Uma reflexão sobre as imagens que os professores de arte mostram aos seus alunos

históricos, institucionais e discursivos (HERNÁNDEZ, 2010, p. 48) com vista a atingir determinados objetivos, logo não são inócuas.

Nos tempos mais recentes temos assistido em Portugal, embora com menos pujança que noutros países, a uma proliferação das publicações sobre arte dirigidas às crianças (Figura 1).

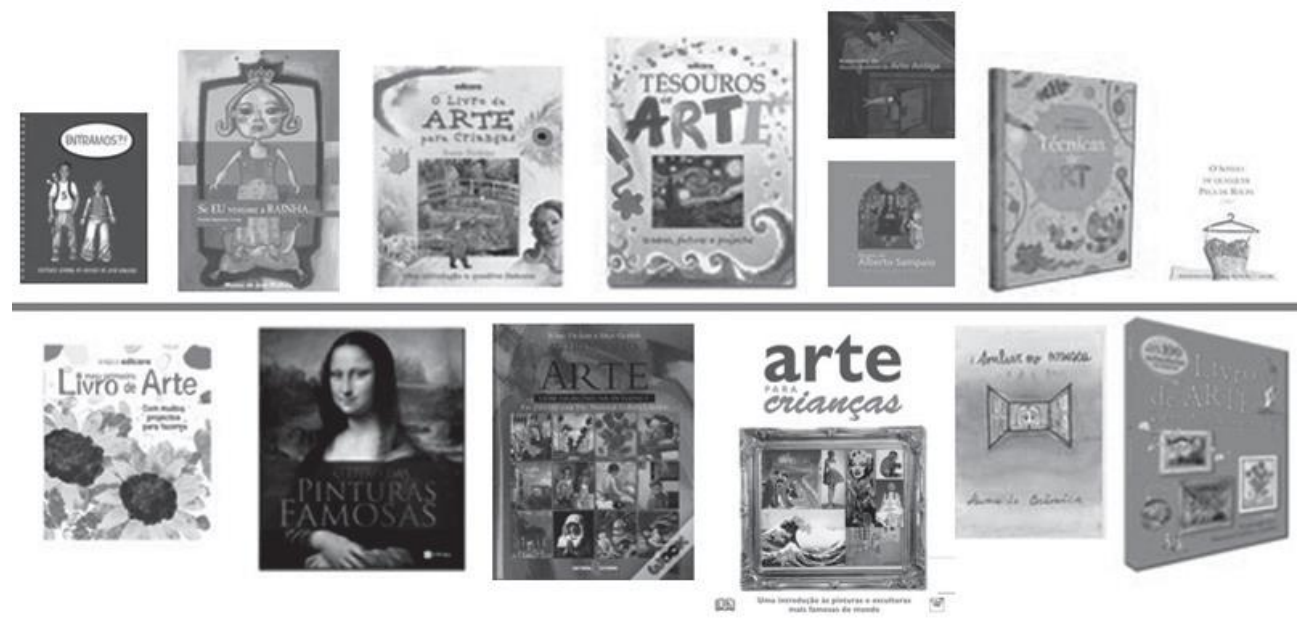

Figura 1: Capas de alguns livros de arte para crianças publicados em Portugal

São essencialmente livros que pretendem sensibilizar e instruir as crianças para os grandes mestres da arte, para a história da arte, ou para as coleções dos museus. Veja-se por exemplo as cada vez maiores secções de livros infantis nas livrarias e nas lojas dos museus, também cheias de objetos "artísticos" prontos a levar para casa pelos seus milhares de visitantes. E tudo isso porque a imagem tem uma primazia absoluta em matéria de aprendizagem, pois tem o poder da ativação da atenção e das emoções do observador, sendo usada como meio de incorporação de conceitos (COSTA, 2006, p. 157-158).

\section{Literacia visual: evolução e perspectivas}

Aquilo que se ensina e aprende na escola tem mudado ao longo dos tempos e as competências que se encaixam no conceito de literacia visual têm evoluído, pelo que podemos identificar três principais momentos nessa evolução: i) a literacia em artes como codificação e descodificação das notações simbólicas; ii) a literacia em artes como resposta às obras de arte; iii) a literacia em artes como consequência do fazer, criar, como resposta e como reflexão em relação aos objetivos, processos e contextos da arte (HONG cit. por REIS, 2009, p. 319).

Revista Digital do LAV - Santa Maria - vol. 9, n. 1, p. 5 - 15. - jan./abr. 2016 ISSN 1983 - 7348 http://dx.doi.org/10.5902/1983734821765 
O conceito de literacia visual, apesar de ter aparecido nos EUA no final dos anos 60, é relativamente recente em Portugal. Aparece em 2001 com a publicação das Competências Essenciais, pelo ministério da educação português, uma espécie de guia para práticas docentes do ensino público, pois até aí o conceito de literacia estava unicamente ligado à capacidade de ler e escrever. A definição apresentada é próxima da perspectiva das multiliteracias (THE NEW LONDON GROUP, 1996), pois encerra em si três áreas de competência no campo das artes: a comunicação, que se relaciona com a capacidade de ler e escrever nas diferentes linguagens das diferentes formas artísticas; a criação, que se relaciona com a capacidade de usar, com sentido e de forma crítica e criativa, os sinais e símbolos associados a cada uma das linguagens; e a compreensão, que se relaciona com a capacidade de entender as obras de arte nas diferentes dimensões do seu contexto.

No entanto a definição do conceito e o que ele implica varia consoante a perspectiva sobre a qual se olha. Fernando Hernández (2007, p. 22), por exemplo, assinala que adquirir literacia visual ${ }^{1}$ deve permitir aos alunos analisar, interpretar, avaliar e criar, a partir das relações estabelecidas entre saberes que circulam pelos "textos" orais, auditivos, visuais, escritos, corporais e, em especial, aqueles vinculados às imagens que saturam as representações mediadas pela tecnologia nas sociedades contemporâneas.

\section{A direcionalidade a imagens}

O conceito de direcionalidade deriva dos estudos fílmicos, onde se colocava sempre a pergunta "quem pensa este filme que és tu?". O conceito de direcionalidade nunca antes tinha sido associado à pedagogia, até Elisabeth Ellsworth o ter feito no seu livro Teaching Positions, de 1997. Aplicar o conceito de direcionalidade ao terreno da pedagogia permite dar visibilidade e problematizar o modo como todo o currículo convida os seus usuários a adoptar posições particulares dentro das relações de conhecimento, poder e desejo² (ELLSWORTH, 2005, p.12).

Aplicar este conceito às imagens, e à pedagogia das imagens em particular, permite-nos perguntar: Quem pensa esta imagem que és tu? A pergunta colocada deste modo pretende indagar sobre como funcionam as dinâmicas de posicionamento no visionamento das imagens: em que lugar te coloca a imagem? Quem se dirige a ti nesta imagem para que te sintas implicado com ela? O lugar que te é designado altera o modo como vês e utilizas a imagem? (ELLSWORTH, 2005; HERNÁNDEZ, 2010). Penso que estas perguntas ajudam o professor a tornar mais claro 
O que nos dizem as imagens que vêm os nossos alunos: Uma reflexão sobre as imagens que os professores de arte mostram aos seus alunos

para si próprio que as imagens que mostramos, e como as mostramos, têm mais influência nos alunos do que à partida poderíamos supor.

\section{Que imagens os professores de arte partilham comigo e o que interpretei quando olhei?}

Ao olhar para as centenas de imagens recolhidas optei por não fazer uma análise estatística das respostas mas sim uma análise qualitativa, pois considero que este tipo de análise permite olhar para além da tirania dos números, olhar com o objectivo de compreender mais do que quantificar. Deste modo criei algumas categorias que pretendem colocar em evidência as concepções de literacia visual que os professores têm, sendo possível vinculá-las com alguns referentes.

\section{A visão mediada}

A grande maioria das respostas revela que as imagens são quase sempre projetadas com um videoprojector e raramente se privilegia o contacto direto, ou não mediado, com o mundo, fruto do acesso à tecnologia e crescente capacitação para a usar. Este modo de visualização traz grandes vantagens para o professor pois apresenta as imagens em grandes dimensões, conseguindo assim prender a atenção dos alunos. No entanto há que ter em atenção que as representações visuais (visão mediada) diferem das percepções do natural (visão não mediada) porque são modos de comunicação intencional, codificados, e porque são a representação de algo, não a coisa em si (WALKER \& CHAPLIN, 2002, p. 42). Este tipo de visualização mediado pela tecnologia não é novo nem é desconhecido dos alunos, pois estão habituados a ver televisão e a visualizar imagens no computador. O que me parece novo nestes resultados é a utilização massiva destes meios na escola, levando a que estas simulações se tornem omnipresentes e se introduzam cada vez mais na nossa experiência de realidade (WALKER \& CHAPLIN, 2002, p. 43).

\section{As imagens da arte e o predomínio da pintura}

É inegável que os professores mostram muitas imagens de obras de arte aos seus alunos. A maioria das imagens enviadas documenta isso mesmo, o que parece corroborar a ideia de Duncum (cit. por REIS, 2009) de que as artes visuais se tornaram um lugar-comum residindo a sua especial importância na sua ubiquidade.

Revista Digital do LAV - Santa Maria - vol. 9, n. 1, p. 5 - 15. - jan./abr. 2016 ISSN 1983 - 7348 http://dx.doi.org/10.5902/1983734821765 
No entanto, verifico que as obras escolhidas encaixam essencialmente nos cânones da História da Arte, sendo normal que a mesma obra seja enviada por diferentes professores de diferentes lugares, ou seja, obras de artistas que alcançaram notoriedade e reconhecimento. A maioria das obras apresentadas é da época moderna e pertence à chamada "arte europeia". Verifico também que há maior tendência para mostrar pintura aos alunos do que qualquer outra forma de arte ou cultura visual. Também os manuais escolares parecem optar por fazer uma seleção idêntica, pois verifica-se que apresentam a pintura como forma de arte privilegiada (RIBEIRO, 2005) ${ }^{3}$.

Deste modo, parece estar esbatida a ideia expressionista de preservar as crianças das obras de arte e da história da arte (AGUIRRE, 2010, p. 37), tendo em conta a presença cada vez maior deste tipo de imagens na vida das crianças. Além dos artistas "incontornáveis" da história da arte europeia há também referências a obras de artistas portugueses, na sua maioria autores do séc. XIX e XX, tais como Sarah Afonso, Nadir Afonso, Eduardo Viana, mas também a artista contemporânea Joana Vasconcelos. A utilização de obras de arte essencialmente figurativas ou, quando abstractas, geométricas, parece basear-se na ideia de que as crianças são seres inocentes e detentores de pouco conhecimento, capazes apenas de entender estas obras destes artistas, com formas e cores básicas, como se estivesse a nascer um novo estilo de "arte para a infância" (AGUIRRE, 2010, p. 38).

\section{O academismo das propostas de trabalho}

Parece haver um paradoxo entre as imagens que são escolhidas e as propostas de trabalho que são sugeridas. As imagens parecem reportar-se a uma visão romântica e simplista da infância enquanto as propostas de trabalho parecem indicar um retorno do academismo à escola, como se o objectivo neste nível de ensino fosse ensinar arte e formar artistas.

Os dados fornecidos pelos professores indicam que grande parte das atividades são orientadas para conhecer a biografia do artista e as suas obras, fazer a cópia de reproduções das obras dos artistas estudados, simular do seu modo de pintar ou repetir procedimentos puramente mecânicos como recortar ou pontilhar; respeitar os cânones de representação do rosto ou do corpo humano; ou estudar dos elementos da forma (Figura 2).

Revista Digital do LAV - Santa Maria - vol. 9, n. 1, p. 5 - 15. - jan./abr. 2016 ISSN 1983 - 7348 http://dx.doi.org/10.5902/1983734821765 
O que nos dizem as imagens que vêm os nossos alunos: Uma reflexão sobre as imagens que os professores de arte mostram aos seus alunos

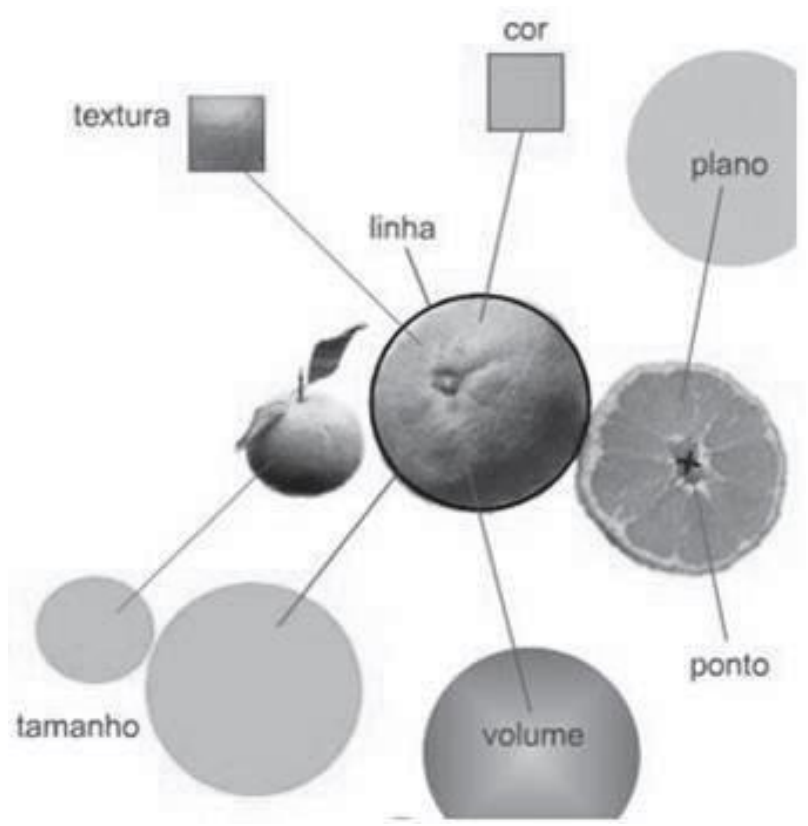

\section{Figura 2: Imagem mostrada aos alunos para estudo dos elementos da forma.}

Verifico com frequência que as obras de arte são apresentadas aos alunos numa perspectiva contextualista e não essencialista, pois são privilegiados os valores extrínsecos e utilitários da arte (ROCHA, 2001). É o que parece acontecer com a recorrente escolha de obras que os professores encaixam na categoria "geometria na arte". São obras que apresentam pontos, linhas e formas básicas como quadrados, rectângulos, triângulos e círculos (Figura 3).
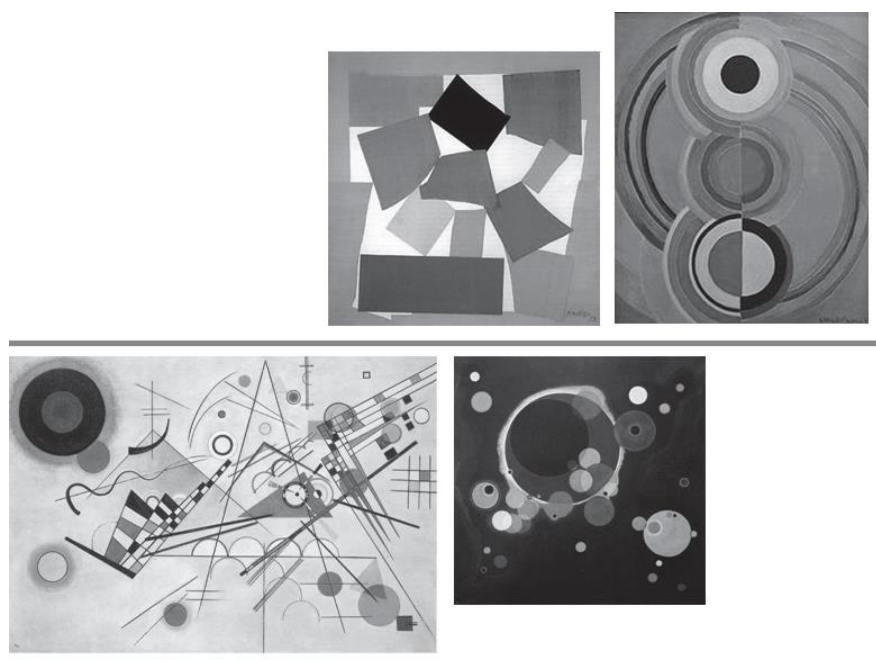

Revista Digital do LAV - Santa Maria - vol. 9, n. 1, p. 5 - 15. - jan./abr. 2016

ISSN $1983-7348$ http://dx.doi.org/10.5902/1983734821765 
Figura 3: Algumas das obras de arte enviadas pelos professores sobre o tema "A geometria na arte"

Tendo em conta as imagens que me foram enviadas, penso não ser abusivo afirmar que a concepção de Educação Artística predominante está orientada para "o conhecimento das artes em vez de usar as artes para aumentar o conhecimento" (AGUIRRE, 2010, p. 39).

\section{A reprodução do aborrecido e o legado dos trabalhos manuais}

Os professores parecem reproduzir de forma imediata as metodologias de trabalho com as quais eles mesmo foram formados, fazendo aquilo a que Acaso (2009, p. 16) chama a reprodução do aborrecido, pois continuam a ser propostas aos alunos atividades como a capa e a sua identificação (Figura 4), ou seja, as mesmas propostas que eu tive enquanto aluno há mais de duas décadas atrás.

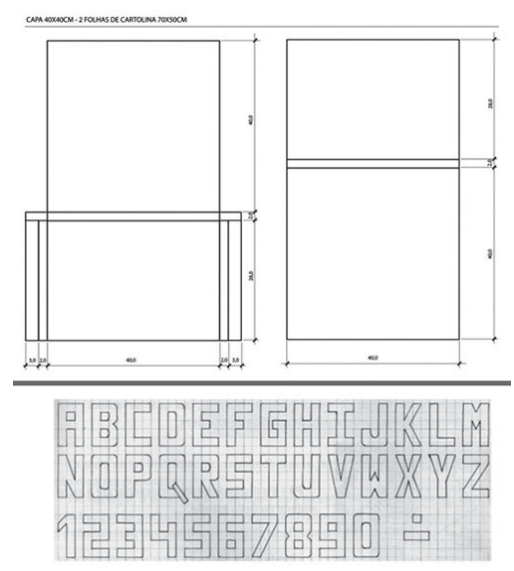

Figura 4: Projeto de uma capa a construir pelos alunos e modelo de letras a construir em papel quadriculado

Outro tipo de atividade bastante recorrente é a elaboração de objetos utilitários, se- guindo um modelo predefinido, dado pelo professor, que garante a qualidade do produto final. Este modo de fazer tem a sua génese nos antigos trabalhos manuais educativos onde se dizia ser importante dar aos alunos as regras e os preceitos mais próprios para realizar as tarefas com perfeição e facilidade, com arte e ciência (LIMA, 1932).

\section{Sobre o que não que se fala}

Revista Digital do LAV - Santa Maria - vol. 9, n. 1, p. 5 - 15. - jan./abr. 2016 ISSN 1983 - 7348 http://dx.doi.org/10.5902/1983734821765 
O que nos dizem as imagens que vêm os nossos alunos: Uma reflexão sobre as imagens que os professores de arte mostram aos seus alunos

De um modo geral, as imagens enviadas denotam algo muito característico na cultura ocidental: a necessidade de manter as crianças à margem da vida real, tentando preservá-las dos problemas sociais, das imagens violentas ou de cariz sexual. Aguirre (2010, p. 38) chama a isso "temas açucarados", pois deixamos que as crianças vivam num mundo sem conflitos, onde tudo é felicidade, paz e bem-estar, ou seja, um mundo de fantasia, cor e alegria. Este não é um problema apenas estético mas, sobretudo, é um problema pedagógico que tem a sua origem na nossa própria concepção de infância. É esta concepção romântica da infância, fundada por Rousseau e Locke no séc. XVII e consolidada durante o séc. XIX, que tem fundamentado em grande medida a resistência dos professores em tratar temas habitualmente associados à cultura visual, como as questões de género e raça, os estereótipos sociais, o prazer ou a representação do corpo, por exemplo (HERNÁNDEZ, 2010).

\section{O que podemos aprender a partir deste estudo}

Este estudo não deverá ser entendido isoladamente mas sim como parte de um conjunto de procedimentos de investigação integrados numa tese de doutoramento que tem por objectivo indagar sobre o papel da escola no desenvolvimento e valorização social da literacia visual. A tese será construída com base em três pontos de vista: os discursos do campo científico da Educação Artística; discursos Administrativos (Projetos Educativos dos Agrupamentos, currículos, documentos oficiais e legislação); e os discursos dos Sujeitos (Professores e Alunos).

O estudo pretende recolher os discursos dos professores. Discursos que eles próprios produziram baseados na sua experiência educativa com as imagens, partilhando-os generosamente comigo. É bom ter a consciência de que a ação de um professor não é inócua. Cada imagem que escolhe, cada atividade que propõe, cada decisão que toma no decorrer da sua ação pedagógica está arreigada nas suas concepções sobre o que é a Educação Artística; sobre o que os seus alunos têm de aprender na sua disciplina; sobre o que é a Literacia Visual; sobre o que pensa quem são os seus alunos, ainda que disso não esteja totalmente consciente.

Com base nestes resultados, podemos celebrar a chegada das imagens de arte à escola. No entanto, o género da pintura domina essas imagens que os alunos vêm na escola esquecendo que, do ponto de vista educativo, uma instalação ou uma fotografia contemporânea podem ser tão formativas como uma pintura (AGUIRRE,

Revista Digital do LAV - Santa Maria - vol. 9, n. 1, p. 5 - 15. - jan./abr. 2016 ISSN 1983 - 7348 http://dx.doi.org/10.5902/1983734821765 
2010, p. 39). De realçar também que as imagens da cultura visual, que inundam o quotidiano dos jovens, não são abordadas nas aulas, permitindo assim que as vivências e as aprendizagens realizadas pelos alunos fora do contexto escolar continue fora da escola, cavando ainda mais o fosso que separa o "dentro" e o "fora" da escola. As propostas de trabalho baseadas em análises formalistas de obras de arte, na aprendizagem de técnicas e sua reprodução mecânica, ou na reprodução de modelos estéticos tidos como "mais adequados" aos alunos assenta na ideia de formar aquilo a que Rogoff (2002) define de "bom olho". O bom olho é aquele que é capaz de discernir, de analisar profundamente, ou seja, o olho do conhecedor que sabe gramática visual; distingue os elementos da forma; e conhece a história da arte, mas tem dificuldade em relacionar, em interpretar, em avaliar ou em criar.

Parece-me que estes resultados apontam para possamos situar as concepções de literacia visual subjacentes à prática dos docentes, em perspectivas de educação artística orientadas para o estudo da história da arte, para a reprodução de objetos, para a aprendizagem de técnicas, ou para a preparação para o trabalho seguindo determinados procedimentos específicos. Espero que este estudo seja um contributo para uma reflexão séria e profunda sobre as disciplinas da área das artes visuais no currículo do Ensino Básico, sobre os conteúdos e sobre as práticas, mas também - e não menos importante - sobre que jovens queremos na nossa sociedade e sobre o nosso papel como professores no seu percurso de vida.

\title{
Notas:
}

\begin{abstract}
${ }^{1}$ Não posso deixar de assinalar a polémica que existe em volta da própria designação (não tanto em volta do conceito de literacia visual. Essa polémica baseia-se especialmente na perspectiva de que a palavra literacia (que se funda na ideia de ler) não deverá aparecer associada à palavra visual, pois as imagens não se lêm, vêm-se! Esta é uma discussão bastante interessante e tratada detalhadamente por Elkins $(2003 ; 2008)$ mas a qual não cabe tratar neste trabalho, embora não a queira deixar passar em claro.
\end{abstract}

2 Para que se tenha uma ideia mais clara sobre a importância que Ellsworth (2005, p. 14) atribui aos efeitos da direcionalidade na escola afirma que se tornou professora porque as raparigas não chegam a ser astrónomas, ou seja, ela considera que a escola the designou uma "direção" simplesmente porque é rapariga e dá vários exemplos sobre isso no seu livro.

${ }^{3}$ Esta tese de Ângelo Ribeiro (2005) refere-se apenas aos manuais escolares de educação visual ( $3^{\circ}$ ciclo o equivalente ás $7^{\mathrm{a}} \mathrm{s}$, $8^{\mathrm{a}} \mathrm{s}$ e $9^{\mathrm{a}} \mathrm{s}$ séries no Brasil, nota dos editores) mas o rápido folhear de um conjunto de manuais escolares de EVT, (acrônimo da disciplina de Educação Visual e Tecnológica, nota dos editores) ainda que sem uma estatística exata, permite-me corroborar estas conclusões.

Revista Digital do LAV - Santa Maria - vol. 9, n. 1, p. 5 - 15. - jan./abr. 2016 ISSN 1983-7348 http://dx.doi.org/10.5902/1983734821765 


\section{Referências:}

ACASO, Maria. La educación artística no son manualidades: nuevas prácticas en la enseñanza de las artes y la cultura visual. Madrid: Catarata, 2009.

AGUIRRE, Imanol. Sobre los usos del arte en la escuela infantil. In VIDA, R.G; VIANA, M. A. M. \& CASTRO, C.G. (Eds.) I Congreso Internacional Arte, Ilustración y Cultura Visual en Educación Infantil y Primaria: construcción de identidades. Granada: Universidade de Granada, 2010, p.35-45.

DEPARTAMENTO DE EDUCAÇÃO BÁSICA. Currículo Nacional do Ensino Básico: Competências Essenciais. Lisboa: Ministério da Educação, 2001.

ELKINS, James. Visual studies: a skeptical introduction. Routledge. Disponível em <http://books. google.com/books?id=rj17dl8lgvuc\&pgis=1> Acesso em 1 jan 2011.

ELKINS, James. Visual literacy. London: Routledge, 2008.

EШSWORTH, Elisabeth. Posiciones en la enseñanza: diferencia, pedagogía y el poder de la direccionalidad. Madrid: Akal, 2005.

HERNÁNDEZ, Fernando. Espigador@s de la Cultura Visual: otra narrativa para la educación de las artes visuales. Barcelona: Octaedro, 2007.

Hernández, F. (2010). direccionalidad y análisis dialógico-performativo frente a los discursos sobre la infancia. In R. G. Vida, m. á. m. Viana, \& c. g. Castro (Eds.), I Congreso Internacional "Arte, Ilustración y Cultura Visual en Educación Infantil y Primaria: construcción de identidades. (pp. 47-59). Granada: Universidad de Granada,

LIMA, A. (1932). Metodologia (Vol. II). Lisboa: Livraria Ferin.

REIS, Ricardo. (2009). The literacy in visual arts: a view about elementary school curriculum in Portugal. International Journal of the Arts in Society, 4(1), 317-328. Disponível em http://ija.cgpublisher.com/ product/pub.85/prod.390. Acesso em 13 de abr 2010.

RIBEIRO, Ângelo. (2005). A imagem da imagem da obra de arte no uso dos manuais de Educação Visual. Dados. Universidade do Minho. Disponível em <http://repositorium.sdum.uminho.pt/handle/1822/3961> Acesso em 1 jan 2010.

ROCHA, M. M. da S. (2001). Educação em arte - concepções e práticas: um estudo sobre 0 acto educativo de professores do $2^{\circ}$ ciclo do ensino básico. Universidade Nova de Lisboa. Disponível em http://run.unl.pt/ bitstream/10362/325/1/rocha_2001.pdf> Acesso 1 jan 2010.

ROGOFF, Irit. Studying visual culture. In N. Mirzoeff (Ed.), The Visual Culture Reader (2a Ed.). London: Routledge, 2002.

THE NEW LONDON GROUP. (1996). A pedagogy of multiliteracies: designing social Futures. Harvard Educational Review, 66(1), 60-92. Disponível em: <http://wwwstatic.kern.org/filer/blogWrite44manilaWebsite/paul/articles/a_pedagogy_ of_multiliteracies_designing_social_Futures.htm> Acesso em 20 jun 2010.

Revista Digital do LAV - Santa Maria - vol. 9, n. 1, p. 5 - 15. - jan./abr. 2016 ISSN 1983 - 7348 http://dx.doi.org/10.5902/1983734821765 
Ricardo Reis

WALKER, John., \& CHAPLIN Sarah. Una introducción a la cultura visual (1 $\stackrel{a}{ }$ Ed.).

Barcelona: Ediciones Octaedro, 2002.

Revista Digital do LAV - Santa Maria - vol. 9, n. 1, p. 5 - 15. - jan./abr. 2016 ISSN 1983 - 7348 http://dx.doi.org/10.5902/1983734821765 